\title{
LA TUMBA DE TRESGUERRAS
}

P O R

\author{
F R NCISCO DE LA MAZA
}

Aracuas a la gentileza del historiador don Luis Chávez Orozco, el InsT tituto de Investigaciones Estéticas se complace en publicar un interesante documento sobre el sepulcro que el célebre arquitecto Francisco Eduardo Tresguerras se hizo en Celaya. El manuscrito es el Inventario de todo el adorno, ormamentos, vasos sagrados y demás cosas pertenecientes para celebrar al Santo Sacrificio de la Misa, existentes en la Capilla de $N$ uestra Señora de los Dolores ubicada en el Cementerio del Colegio de $N$. S. P. S. Francisco, sirviendo esta capilla de ultima Estación en el Santo $V$ ia-Crucis; siendo costeada dicha Capilla desde sus cimientos y adomo interiar del peculio propio de don Francisco Eduardo Tres-Guerras.

Hizo el inventario su nieto don Tomás Vélez y Tresguerras, al año $y$ diez meses de la muerte del artista, anotando todas las "pinturas, espejos y curiosidades" que habia.

Dos noticias, por lo pronto, nos da el título del doctumento: que el sepulcro-capilla era el fin de un Via-Crucis existente en el atrio de San Francisco de Celaya, hoy destruido al derribar las bardas, abrir calles $y$ 
convertirlo en jardin y de que los adornos de la tumba fueron puestos $y$ costeados por el propio Tresguerras. Esto viene a aclarar las dudas que habia sobre si ese gusto de bazar funerario que ostenta la capilla era debido más bien a la familia y descendientes que al mismo arquitecto. $Y$ es esto un dato interesante porque nos confirma el intimo barroquismo que anidaba en el alma de ese cré́do paradigma del Neoclásico mexicano.

Estudiando con detenimiento y sin los prejuicios ditirámbicos a que estamos acostumbrados por la bibliografía y tradición de Tresguerras, podemos llegar a la conclusión de que el arquitecto, pintor y escultor de Celaya no tiene nada de clásico ni de neoclásico; fué un hombre barroco, no a la manera del gran Barroco mexicano, sino a la del Barroco europeo. Todas sus obras de arquitectura son copias o inspiraciones de los artistas barrocos españoles e italianos. Los Churriguera, Bernini y Borromini, Fontana y Maderno no hubieran desdeñado firmar obras de Tresguerras, y su célebre iglesia del Carmen, si estuviese en Roma, seria una de tantas iglesias barrocas de la Ciudad de los Papas. ¿ Por qué, entonces, Tresguerras se escandaliza y abomina, en sus escritos, de esos artistas y cree ser un obediente hijo de Vignola y de Vitrubio? Por la una parte, por seguir la corriente de su tiempo; por la otra, porque aunque él no lo diga, si estudiaba los libros de Vitrubio, también se encantaba con el gusto barroco de los italianos en el adorno y en las travesuras nada clásicas de tantas soluciones arquitectónicas que ellos y Tresguerras se permitieron en sus obras.

Y una última prueba de este barroquismo de Tresguerras nos la da su tumba. Quiso allí amontonar cuantos objetos satisfacían sú pasión interna de ese bazarismo hogareño que inundaba las salas, las asistencias, los roperos y vitrinas de nuestras señoras del siglo $\mathbf{x} 1 \mathbf{x}$, que no puede estar más lejos de la depuración neoclásica. El lector verá en el Inventario la enorme cantidad de curiosidades con que llenó su sepulcro, que resulta el último "documento" por el cual podemos conocer más de cerca al artista celayense. Alli, sin trabas ni concesiones, convencido de que hace algo intimo y respetable para todos, desborda sus gustos personales y no se limita a lo que su época y sus libros le impusieron en vida: Es como un testamento valiente $y$ sincero, como una confesión liberatoria de sentimientos ahogados por el medio. Es un gritar: "también esto me gustó", en desafío al ambiente.

Dice el citado inventario que la capilla tiene su portada "de cantera primorosamente labrada a lo moderno", es decir a lo clásico, y pase a 
enumerar el contenido. Desde luego, lo primero que llama la atención es un gran cuadro de la Virgen de los Dolores, pintado por el propio Tresguerras, con un marco "de talla dorada $y$ en los lados copetes, calados y embutidos vidrios finos, azogados", y asi serán los marcos de las demás pinturas, desde Cristo y los Apóstoles, a San Francisco y San Eduardo, sus santos epónimos. Después viene "un marco ochavado, siguiendo la figura de la bóveda, de madera, con molduras, dorado y embutido de vidrios finos azogados y en el medio una corona de flores con sus lazos muy curiosa, de madera y moldturas doradas y embutida de vidrios finos azogados". ¿ No es esto un afán decorativo propio del barroco? Lá cantidad de espejos y cuadros es enorme, todos con marcos "dorados y tallados". ¿ No eran estos los retablos que tanto destruyó?

Hay grat cantidad de copas, vasos, jarras de cristal, mexicanas y europeas, así como cerámica oriental, española y poblana, todos con sus asientos "en bases de madera dorada y rellena de espejos", y el blanco del altar era "de madera tallada y con mucha curiosidad embutidos tres platos de cristal y varias lunas en los calados de las molduras". Se citan muchos vasos de cristal de Venecia y jarros "abronzados de Sajonia", así como tibores y frascos chinos y varios "leoncitos de china blanca" $y$ "dos conserveras azules de China y sobre ellas dos floreros de Sajonia".

También campean versos, poemas $y$ sonetos, escritos con tinta o al óleo, en cartones y maderas, todos enmarcados con maderas taraceadas. i Hasta muerto quiso estar rodeado de sus pobres versos! Hay algunos que están escritos al revés de proyectos arquitectónicos. En el momento en que le venía la inspiración allí escribia. Leemos que había tinteros y "pescaderitas de China", y otras docenas de curiosidades fatigosas de enumerar. Pero Iqué más que las "sesenta flores de madera doradas y embutidas de estrellas de espejos" de la bóveda! ¿No llenaban los artistas barrocos sus bóvedas de estrellas y rayos para hacer su "cielo"? Y el candil es "de cristal, bien adornado de lianas de almendras y otras prendas de diferentes hechuras", colgando de "una curiosa piña de madera dorada'.

Pero el colmo es el lavabo de la sacristia. Es, según el inventario, "un curioso aguamanil con su tibor de China blanca, embutidas muchas conchas chichicles, un caracol grande y. un platón de China, azul, y una conservera de lo mistno". Pero no dice el nieto que es una colina de piedra de juguete, en la que, además de las conchas y talaveras van mu- 
nequitos $y$ animales pegados en donde se representan, por medio de minúsculos objetos, todos los estilos $y$ todas las épocas.

Ya que en vida y en obra no pudo Tresguerras salirse de las normas académicas, descansó en su sepulcro, no sólo las fatigas de la vida, sino el intimo cosquilleo de jugar al barroco haciéndose un mundito aparte para él solo, lleno de adornos y preciosas baratijas que no cabian en su estudio de arquitecto.

He respetado la ortografía del documento por considerarla interesante en sus barbarismos y llamo la atención sobre la forma del lenguaje, lleno de diminutivos como "copita", "pichelito", "botelloncito", en fin, esa serie de incansables "itos" con que hablamos los mexicanos y que le dan una amabilidad deliciosa al duro lenguaje de los españoles.

Por último, quiero hacer notar algo que no sabiamos: que al morir Tresguerras no fué enterrado en su tumba, sino bajo un árbol de la huerta de los agustinos, $y$ hasta un año después fué llevada su momia a su propia y última morada. No hay que olvidar que murió del cólera y aunque fuese el más admirado y respetado de los celayenses, sufrió, como todos, un pequeño ostracismo en los aledaños de la ciudad, en espera de que el contagio de la terrible epidemia desapareciera.

Con el documento en la mano he hecho el cotejo de los objetos de la capilla $y$ he anotado los que han desaparecido, unos por necesidad ineludible del tiempo y otros por el descuido de sus guardianes.

\section{DOCUMENTO}

Inventario de todo el adorno, ornamentos, vasos sagrados y demás cosas pertenecientes para celebrar el Santo Sacrificio de la Misa, existentes en la Capilla de Nuestra Señora de los Dolores ubicada en el Cementerio del Colegio de N. S. P. S. Francisco, sirviendo esta Capilla de última Estación en el Santo Via-Crucis; siendo costeada dicha Capilla desde sus cimientos y adorno interior del peculio popio de Don Francisco Eduardo Tres-Guerras.

Inventario de todo lo existente en la Capilla de Nuestra Señora de los Dolores, cita en el Cementerio del Convento de N. S. P. S. Francisco de esta Ciudad de Celaya, fabricada, adornada de excelentes pinturas, 
espejos, curiosidades, costosos ornamentos y vasos sagrados, todo costeado del propio peculio de su fundador Dn. Francisco Eduardo Tres-Guerras.

Hecho a solicitud de Dn. Tomás Veles y Tres-Guerras. Hoy quince de Mayo del año de Mil ochocientos treinta y cinco.

Primeramente la fábrica de la Capilla y Sacristia, toda de mamposteria, de bóvedas en figura obalada, con su portada de cantera primorosamente labrada a lo moderno; tiene de alto siete varas, de largo cinco y media varas $y$ de ancho cinco varas y una quarta.

It. en la testera de la Capilla, una torrecita de un arco, con su campana de llamar a Misa, con peso de una arroba.

It. su puerta de dos manos, de madera buena, colgada con nudos de fierro, con su chapa, llabe $y$ en el medio dos obalos con sus rejas de fierro $y$ vidrios finos, ${ }^{x}$ de tres cuartas de alto $y$ casi media vara de ancho.

It. En el Altar, la Imagen de Nuestra Señora de los Dolores, pintada a) óleo de mano del fundador de dicha Capilla, como también lo son las demás imágenes que se referirán en este inventario; tiene este lienso cuatro varas de largo y tres de ancho, marco de taya dorado y en los lados y copetes calados y embutidos vidrios finos asogados.

It. El fondo o testera está entapisado de damasco morado hasta donde finalisa el lienso y lo demás hasta el banco del altar de terciopelo labrado del mismo color. ${ }^{*}$

It. Un marco ochavado siguiendo la figura de la bóveda, de madera con molduras, dorado y embutido de vidrios finos asogados y en el medio una corona de flores con sus lasos, muy curiosa de madera, molduras doradas y embutida de vidrios finos asogados.

It. En ambos lados está adornada de lo siguiente: dos platos de cristal asogados y embutidos en sus hacientos de madera dorados. Dos pantallas mejicanas con sus vidrios asogados de dos tercias de largo y una cuarta de ancho, con sus arbotantes de cristal y candeleros de ojalata. Dos espejos lunas españolas, de cristal amolado, marcos y copetes de ma-

1 Los vidrios han desaparecido.

2 Ahora es un damasco de color rojo, así como el terciopelo.

3 Una de las pantallas está desprendida de su sitio y tirada en el suelo. 
dera, dorados y embutidos de cristales asogados, de una vara de altos y tres cuartas de ancho, con cuatro arbotantes de latón; descansan estos espejos en dos curiosos repisonsitos de madera tayada, pintados y dorados con dos espejos de a medio pliego en el centro y al lado de cada uno dos tiras de espejos del mismo tamaño y entre las molduras tiene embutidas cuatro estampas romanas, iluminadas y con sus vidrios.

\section{Banco y Sotabanco}

Dos vasos de cristal labrado de venecia, pintados de esmalte en cada uno de los cuatro lados, dorados sus bordes, tapas de platos de cristal, de una tercia de largos y seis sexmas de anchos y sobre de estas tapas dos jarroncitos de cristal labrado; están hacentados estos vasos con sus basas de madera doradas y embutidas de espejos. ${ }^{5}$ Cinco miniaturas, la de enmedio con su rafaguita dorada con la imagen de Nuestro Divino Salvador; las otras un santo Ecce-Homo, una Dolorosa, San Ignacio y San Francisco $\mathrm{X}$ avier, todas con sus vidrios $\mathrm{y}$ ovalitos dorados. ${ }^{*}$ Siete presentallas ${ }^{7}$ de plata. Una jaulita pequeña.

It. El banco o mesa del altar es de madera tayada y con mucha curiosidad embutidos tres platos de cristal asogados y varias lunas de espejos embutidos en los calados de las molduras; en el medio un cajón con llabe $y$ dos a los lados.

It. El sotabanco con dos graditas forradas de raso blanco bordado, con sus molduras y cuatro perillitas de bronce doradas."

It. La mesa de altar y gradas está adornada de lo siguiente: en el medio un nicho ochavado de tres cuartas de largo y una vara de ancho, con su vidriera de medio punto y en lo interior cubierto de tiras de espejos, dorado el fondo y muy curiosamente pintado, con un Niño Dios de alabas-

4 Faltan algutias "tiras" de espejos y la madera tallada esta muy destrífia.

5 No existen.

6 Sólo existe la miniatura de la Dolorosa, sin vidrio ni ovalito dorado. .

7 "Ofrenda o voto que hacen los fieles a Dios o a los santos. Ex-voto" (Dics cionario de la Lengua Española.)

8 No existe.

9 No existe. 
tro, varios querubines y chichicles sobre que está acostado. ${ }^{10}$ En el copete un Santo Cristo de marfil, como de una sexma, con su rafaguita de plata, montadas algunas piedras blancas, y en la circunferencia otra de ojalata cont botones de concha, sirviéndole de respaldo un platito de cristal con el fondo dorado. 11

It. Dos botelloncitos de vidrio cuajado de a una cuarta.

It. Dos copas de cristal, la una con tapa.

It. Dos vasos cuajados de a cuartillo.

It. Dos pichelitos de lo mismo. ${ }^{12}$

It. Dos vasos de vidrio con dos tinteritos de lo mismo.

It. Dos leoncitos de china blanca.

It. Seis conserveras de China.

It. Dos floreros de cristal ctajado.

It. Dos posuelos abarrilados idem.

It. Dos tazas calderas, con dos pichelitos de China.

It. Cuatro frascos de China azul.

It. Dos jarros Saxonia abronzados.

It. Dos pastorcitos de cera.

It. En la grada, bajo los lados del altar, hay dos pares de tibores de china, dos con tapas.

It. Dos conserveras azules de china sin tapa y sobre ellas dos floreros de Saxonia.

It. Dos sonetos en sus marcos sin vidrios. ${ }^{13}$

It. En los dos lados de esta Capilla está entapisado de indiana morada y el friso es de papel cartón moderno y adornados de lo siguiente : doce lienzos de dos tercias de largo y media vara de ancho, de madera los mar-

10 El ochavo, o sea el copete del nicho, está perdido; resta la vidriera de medio punto y el bello Niño Dios de alabastro tiene alrededor tres preciosos querubines de madera. Está acostado sobre siete piedras de curzo.

11 Exibte el copete osn aigwois bolono de concha. E1 Cristo de marfil ha desaparecido.

12 El pichol eg. "un raso alto y retondo, nis ancho del surolo que de la boca con su tapa engoznada en el remate del ase":

13 No existen aude "low botelloncitos" hasta estos sontetos. 
cos, pintados y dorados, con vidrios, menos dos, en que están pintados los doce apóstoles; descansan estos lienzos en una moldura pintada y dorada y en ella están doce arbotantes de cristal y ojalata. ${ }^{14}$ Dos espejos españoles de una vara de largo y tres cuartas de ancho, vidrios amolados, marcos y copetes de madera calados, dorados y embutidos de vidrios finos asogados. Al pie de estos dos espejos están dos pescaderitas de china azul, embutidas en sus asientos de madera tayada y dorados. ${ }^{15}$ Dos lienzos del Salvador y la Virgen, de una vara de largo y dos tercias de ancho marcos de madera pintados y dorados, al óleo, con vidrios y al pie de cada marco dos primorosas miniaturas de la letania con sus vidrios.

It. Dos liensos pintados al óleo, uno del Descendimiento y otro de la Sepultura de Nuestro Señor Jesucristo, de más de una cuarta de largo y cinco sexmas de ancho, con sus vidrios y marco de madera fina. ${ }^{10}$

It. Dos lienzos pintados al óleo de los santos nombres de Jesús y Maria, del tamaño de medio pliego, marcos chapeados de madera fina, con sus vidrios. ${ }^{27}$

It. A los pies de estos lienzos dos sonetos pintados en tecsele montados en madera tayada y dorada. ${ }^{18}$

It. Dos sonetos pintados al óleo y lo mismo los marcos, de más de tres cuartas de largo y una tercia de ancho, sin vidrios y en los copetes dos curiosas miniaturas.

It. Dos espejos de a tercia, con marcos dorados.

It. Dos cuadritos, uno de la Asumpsión y otro de Señor San José, con vidrios y marcos de tampisirán. ${ }^{10}$

It. Una estampa romana de a pliego del Tránsito de Nuestra Señora, iluminada, con vidrio y marco dorado y embutido de espejos, puesta en

14 Existen solamente cinco apóstoles sin sus marcos, los demás están en poder de los padres franciscanos.

15 No existen.

16 No existen.

17 Actualmente, debido a la humedad, han sido trasladados a la casa de los padres franciscanos.

18 La palabra tecsele no la he encontrado en ningún diccionario; parece se refiere a pintura en acuarela sobre papel grueso.

19 No existen. El "tampisirán" no es sino el tapincerán. 
un respaldo de madera aforrado de tela con su brichito ${ }^{20}$ y dos arbotantes de cristal y. ojalata y su rotuloncito al pie, adornado con dos botoncitos de concha. 21

It. La auténtica de las indulgencias que se han consedido a esta Capilla, de dos tercias de largo $y$ tres de ancho, con vidrio y marco de madera fina. 22

It. Dos sonetos en papel cartón.

It. Del lado de la sacristía y arriba de su puerta un lienso de N. P. S. Francisco de tres cuartas de largo y media vara de ancho, con vidrio, marco de madera fina y en el copete un curioso relicario y en el medio un obalito del Divino Rostro. ${ }^{23}$

It. A sus lados dos lienzos de más de medio pliego, uno de Señor San José y otro de San Eduardo, con sus vidrios, marcos y copetes de cristal asogado. 24

It. El retrato verdadero de la Sma. Virgen de media vara de largo y una tercia de ancho, con vidrio, marco de madera fina y debajo su soneto pintado en una tablita. ${ }^{25}$

It. En la manpara de la sacristía el retrato de la venerable Madre Agreda, en estampa romana de a pliego, con marco dorado y embutido de cristal asogado. En los lados del altar, dos cóncavos con sus fondos de platos de china azul. ${ }^{26}$

It. En los ochavos del cielo de la bóveda hay setenta flores de madera doradas y embutidas de estrellas de espejos. ${ }^{27}$

20 Brichito, hoja angosta y sutil de plata o de oro para galones y adornos.

21 No existen.

22 La auténtica fué dada el 27 de febrero de 1818 por fray Bernardo del Espiritu Santo, obispo carmelitano de Sonora, seguramente cuando iba camino de su diócesis.

23 No existe.

24 Sólo existe el cuadro de San Eduardo, muy maltratado.

25 No existe,

26 El retrato de la Madre Agreda no existe, aunque si los platos de China.

27 Están completas pero varias muy destruídas. 
It. Un candil grande de cristal, bien adornado de lianas de almendras y otras piedras de diferentes hechuras, con seis arbotantes de lo mismo.

It. Tiene este candil una curiosa piña de que está colgado de madera dorada y toda embutida de vidrio asogado y pende de una barilla de fierro. 28

It. Dos candiles iguales de ojalata con espejos en sus basas, arbotantes y pendientes de sus piñas de madera dorada y con cuatro carruchas. ${ }^{20}$

It. Sobre la mesa del altar su ara cuadrada de media vara, forrada de contense. ${ }^{80}$

It. Al Pie del aitar una campanita con su cadena.

\section{Sacristía}

Tiene de largo lo mismo que la Capilla, de ancho más de dos varas y de alto correspondiente de bóveda. ${ }^{31}$

Una mesa para poner y guardar los ornamentos, de dos varas de largo, una de ancho y una y media de alto, con tres cajones con chapas, yaves y estiraderas.

It. Un curioso aguamanil con su tibor de talavera, llave de bronce, adornado de cuatro leoncitos de china blanca, embutidas muchas conchas chichicles, un caracol grande y un platón de china azul y una conservera de lo mismo. 2

It. Dos salvillas o asafates para lavarse las manos, una de china y otra de talavera. ${ }^{\mathbf{3 8}}$

28 No existe; solamente la "curiosa pifia" y un candil moderno.

29 No existen.

30 No existe.

31 Hoy está tapada hasta su mitad por un muro.

32 Este aguamanil está hecho de piedras pegadas en donde van los objetos dichos, más algunos vasos de porcelana. La palabra "chichicle" usada ya antes, es un nahuatlismo derivađo, según interpretación de Wigherto Jiménez Moreno del verbo tsitsica tomanitla, que quiere decir, atorar o meter algo apretado en un agujero y cuyo participio tlatzitzictli, atorado, metido en algo, al españolizarse resulta tlachichicle, perdiendo después el prefijo tla. Alude a la inçrustación de las conchas en las piedras det lavabo.

33 No existe. 
It. Un embutido en la pared con plato de china azul y sirve a una copa de cristal con su tapadera. ${ }^{34}$

It. Una imagen de escultura de Nuestro Señor Jesucristo con su peana de tampizirán y ojalata enconchada. ${ }^{\text {as }}$

It. Otro santo Cristo de madera, en su baldoquín y a sus pies una estampa romana de Nuestra Señora de a media vara, con vidrio y marco de tampicirán. ${ }^{\text {se }}$

It. Otro Santo Cristo romano con su cruz enconchada. ${ }^{87}$

It. Una estampa del Señor del Huerto con su vidrio y marco de madera fina, de a medio pliego.

It. Un clavijero para las toayas.

It. Un plumero para sacudir.

It. Una linterna mediana.

It. Una escalerita.

It. Una cajita de ojalata con hislabón, piedra yesca y pajuelas. ${ }^{28}$

\section{Adorno del Altar}

Dos atriles de ojalata con el labatorio y último Evangelio, manuscritos, con sus vidrios.

It. Dos candeleros hechos de dos copas de vidrio y ojalata.

It. Dos pares de candeleros de vidrio de una cuarta.

It. Dos pares dichos, del mismo tamaño, de cristal.

It. Tres pares dichos, de a tercia, de cristal.

It. Un par dichos de metal amarillo.

It. Un par dichos de estaño.

It. Tres candeleros de latón fino.

It. Unas despaviladeras con su platito.

It. Dos apagadores de ojalata.

It. Veinte chorreaderas o cubos de ojalata para dichos candeleros.

34 No existe la copa de cristal.

35 No existe.

36 No existe.

37 No existe.

38 Ninguno de estos objetos; como es natural, no existen.

39 No queda nada de todo este adorno del altar. 


\section{Ornamentos}

Uno de tela, fondo blanco, todo floreado, habiado de todo, con galón de oro y muy bien tratado.

It. Otro de tela nacar, con galón de oro y lo mismo que el anterior.

It. Otro de tela blanca, que aunque se tiene por de segunda, está superior, con galón de oro y bien tratado.

It. Un ornamento de segunda, encarnado, de terciopelo labrado, senefa de fondo azul bordada con galón angosto de oro.

It. Otro idem, de raso morado, adornado con pepitilla y costillejos de oro. ${ }^{40}$

It. Otro de terciopelo de recorte negro, adornado de cinta azul y plata. Todos estos ornamentos están habilitados de sus correspondientes manipulos, estolas, paños de cálisés y bolsas de corporales.

It. Cuatro frontales, uno verde, otro blanco con botones de concha, otro morado con pepitilla todos tres, otro negro de recorte, con sinta azul y plata.

It. Un frontal de indianilla.

It. Dos palias de primera bordadas en raso blanco, con sus respectivos paños.

It. Dos moradas bordadas.

It. Dos blancas de segunda con galón.

It. Dos negras de terciopelo.

It. Cinco amitos con sus listones.

It. Cuatro albas.

It. Tres síngulos.

It.' Ocho corporales.

It. Dos paños de ara.

It. Treinta purificadores.

It. Dos guardapolvos.

It. Dos tohayas, una de bramante $y$ otra de cotense.

40 Las pepitillas son las borias, llamadas así por recordar las pepitas de maiz. Costillejos son las tiras doradas que sirven de armazón a las casullas. 
It. Dos manteles del altar, uno de bretaña y otro de coquillo con sus encajes. 4

It. Dos misales, uno de primera, iluminado de mano del fundador, $y$ otro de segunda, bien tratados. 12

It. Un suplemento de misas, manuscrito de mano del fundador.

It. Dos alfombras, una de lana ya usada y otra de jamán estampado, del tamaño de la grada del Presbiterio del altar.

It. Un tapete superior y nuevo, que cubre el mismo presbiterio.

It. Ocho pares de vinajeras de diferentes clases y un par con sus bocas y tapas de plata, con cinco platillos.

It. Dos hostiarios, uno de metal con su perilla de plata y otro de ojalata.

It. Un frasquito de vidrio labrado para el vino.

It. Al lado de la sacristía está embutida una caja de cedro con su chapa y llave.

\section{Vasos sagrados}

Un calix de plata, dorado, calada la sobrecopa, con patena y cucharita, con peso de tres marcos y seis onsas.

It. Otro calix de filigrana, muy superior, dorado el fondo, con patena y cucharita, con peso de tres marcos.

It. Dos cajas de guardar los cálises, forradas de badana, con sus aldavitas.

En el medio de esta Capilla está el sepulcro en que descansan los restos del finado fundador don Francisco Eduardo Tres-Guerras, el qual murió el sábado tres de Agosto del año de Mil ocho cientos treinta y tres a las nuebe de la noche, asistido de todos los socorros y auxilios espirituales, recibió con tiempo y en su entero conocimiento todos los santos sacramentos. Se sepultó su cuerpo el dia cuatro de dicho, en la huerta del Convento de $\mathrm{Sn}$. Agustín, y el día treinta y uno de Octubre del año de

41 El coquillo es un mantel a modo de tela labrada o alemanisco, generaimente con adorno de nido de abejas.

42 Por desgracia este misal iluminado por Tresguerras ast como el suplemento citado despues, no existen. 
mil ocho cientos treinta y cuatro, después de exumado su cadaver, con un solemne funeral se depositaron sus restos en dicho sepulcro en donde espera la general Resurrección.

It. En un lado de dicho sepulcro está el Epitafio en que se dice un rasgo de las qualidades que adornaban a dicho fundador.

\section{EPITAFIO}

Dcjó ya de existir. En esta fosa

que él mismo se labró, Tresguerras yace,

y ni más su pincel forma el buen gusto

ni la escuadra lucir puede su mano;

empero viven aún sus grandes obras,

vive en ellas el hijo de Celaya,

eminente pintor, sabio arquitecto,

que de su siglo mereció el aplauso;

ya los frutos cubrirá de asombro;

hízose por sí sólo todo un genio,

como otro Miguel Angelo su nombre,

libre de olvido se conserva y guarda. ${ }^{45}$

43 Seguramente que de este epitafio, hecho tal vez por su nieto, comenzó la sostenida y mal fundada fama de que Tresguerras fué "el Miguel Angel mexicano". 
DOI: http://dx.doi.org/10.22201/iie.18703062e.1951.19.519

Inventavio de todo lo exis-

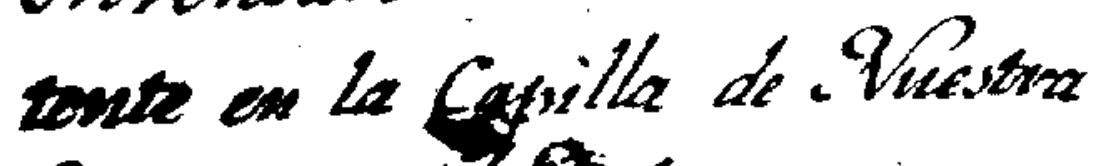
Ceniora de la Gáores, cita en el Cementerio Sel Comento \&

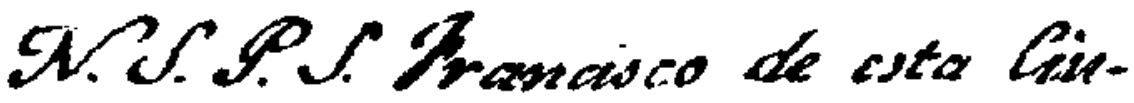
dab at Celaya, fribicado. astornada of excetenteo pimturas, espejos, curiosidades, coitosos oruamen. tor y vaves sagritos, to do corteals det propio peentio de su fundason

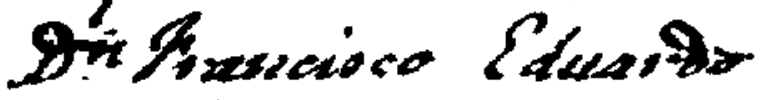
Zrese Guerras.

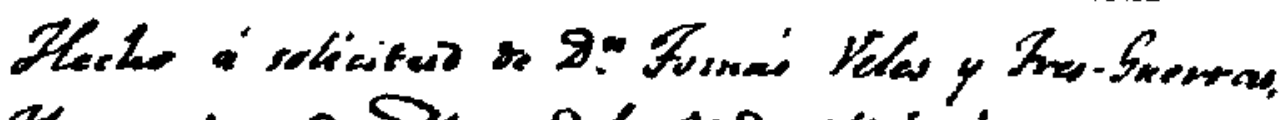

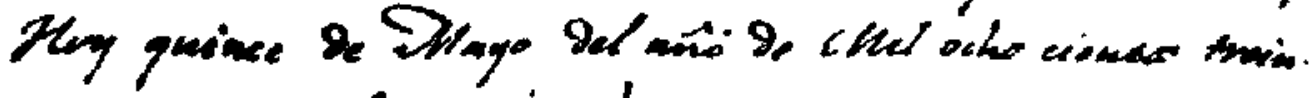
necinas.' 
DOI: http://dx.doi.org/10.22201/iie.18703062e.1951.19.519

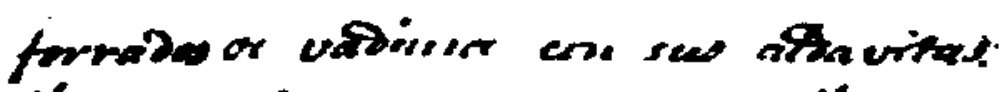

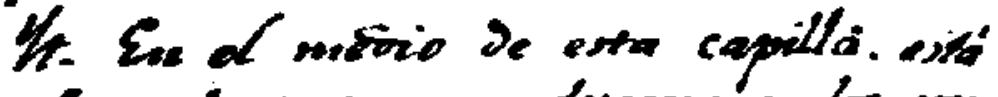

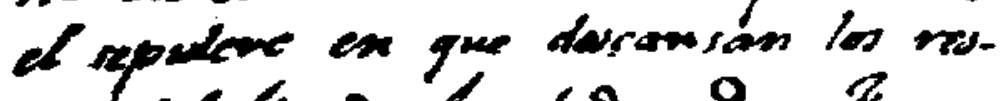

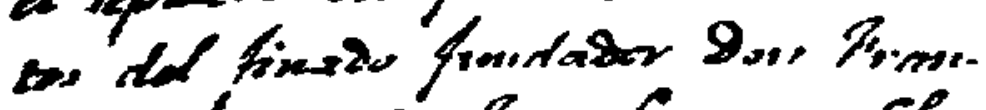

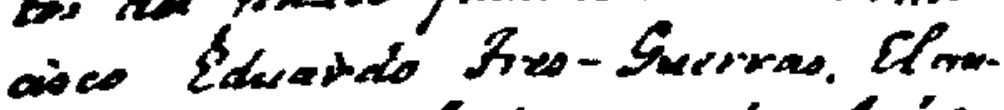

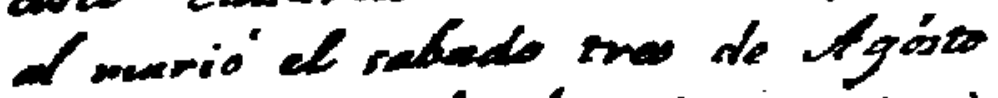

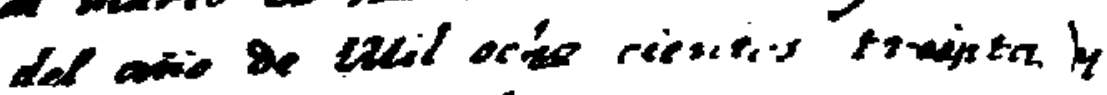

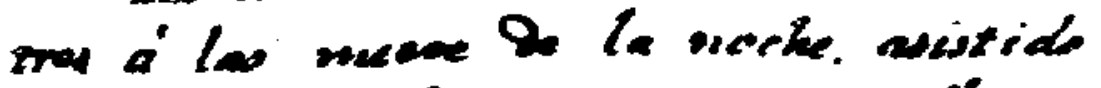

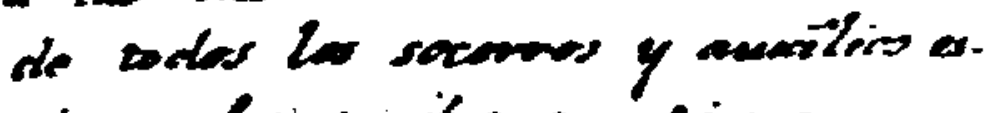

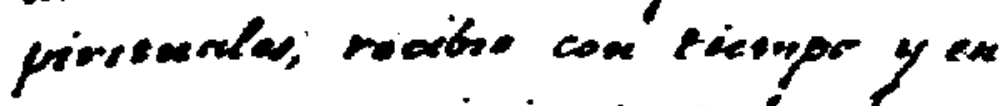

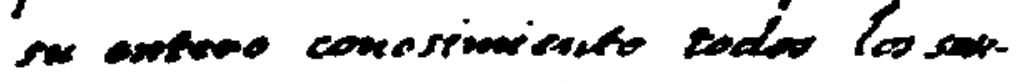

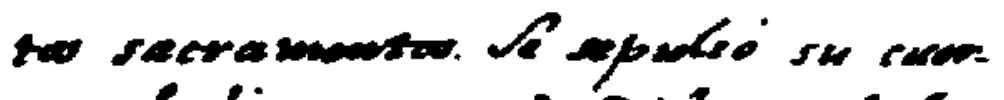
po el tie curceso de girhe an lo har

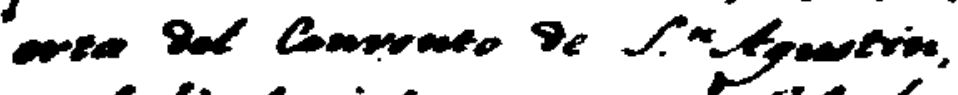

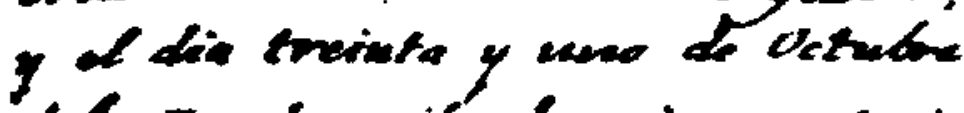

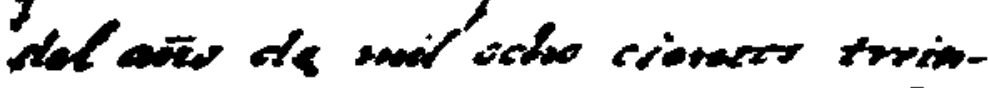

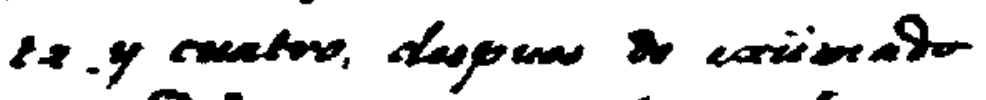

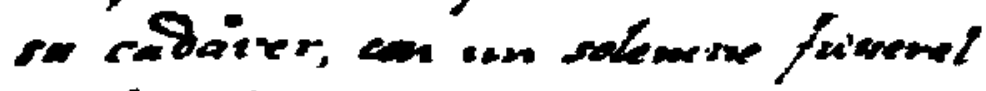

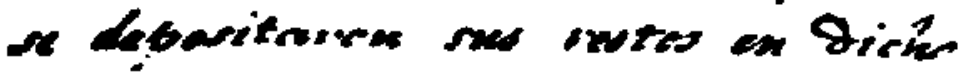
sepowters en bonde coporia la gem ral hasumercion.

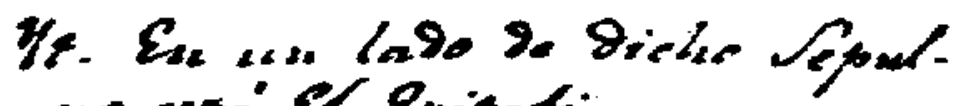
ceo wrie' 21 Qpitatio on gisen the w mege to lo quatidist

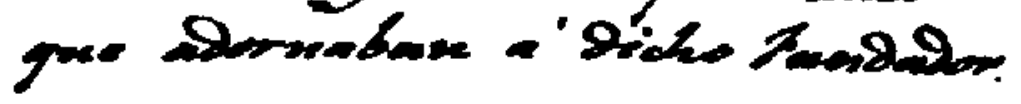


DOI: http://dx.doi.org/10.22201/iie.18703062e.1951.19.519

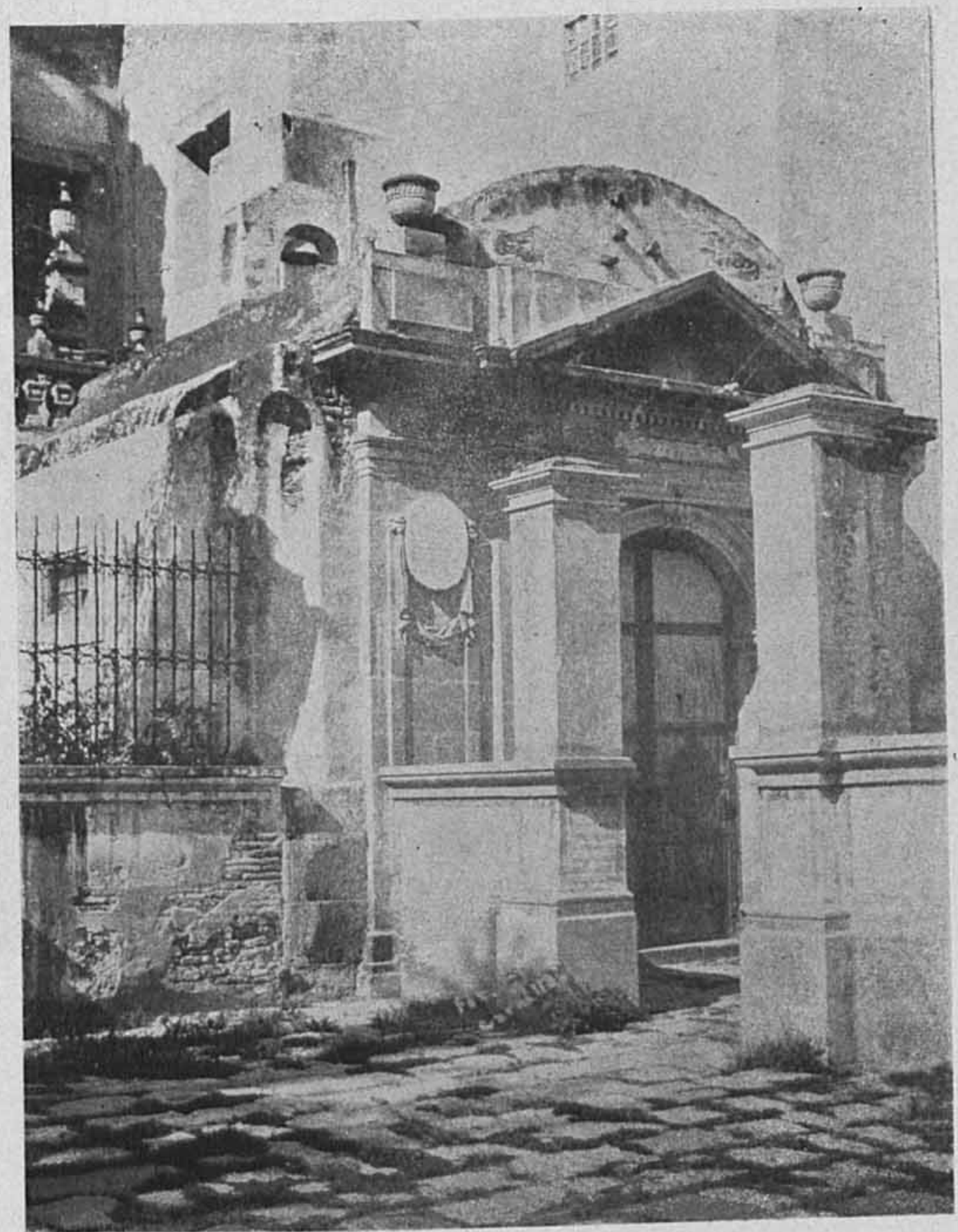

1. Fachada de la capilla-sepulcro de Tresguerras.

(Foto Carballio.) 
DOI: http://dx.doi.org/10.22201/iie.18703062e.1951.19.519

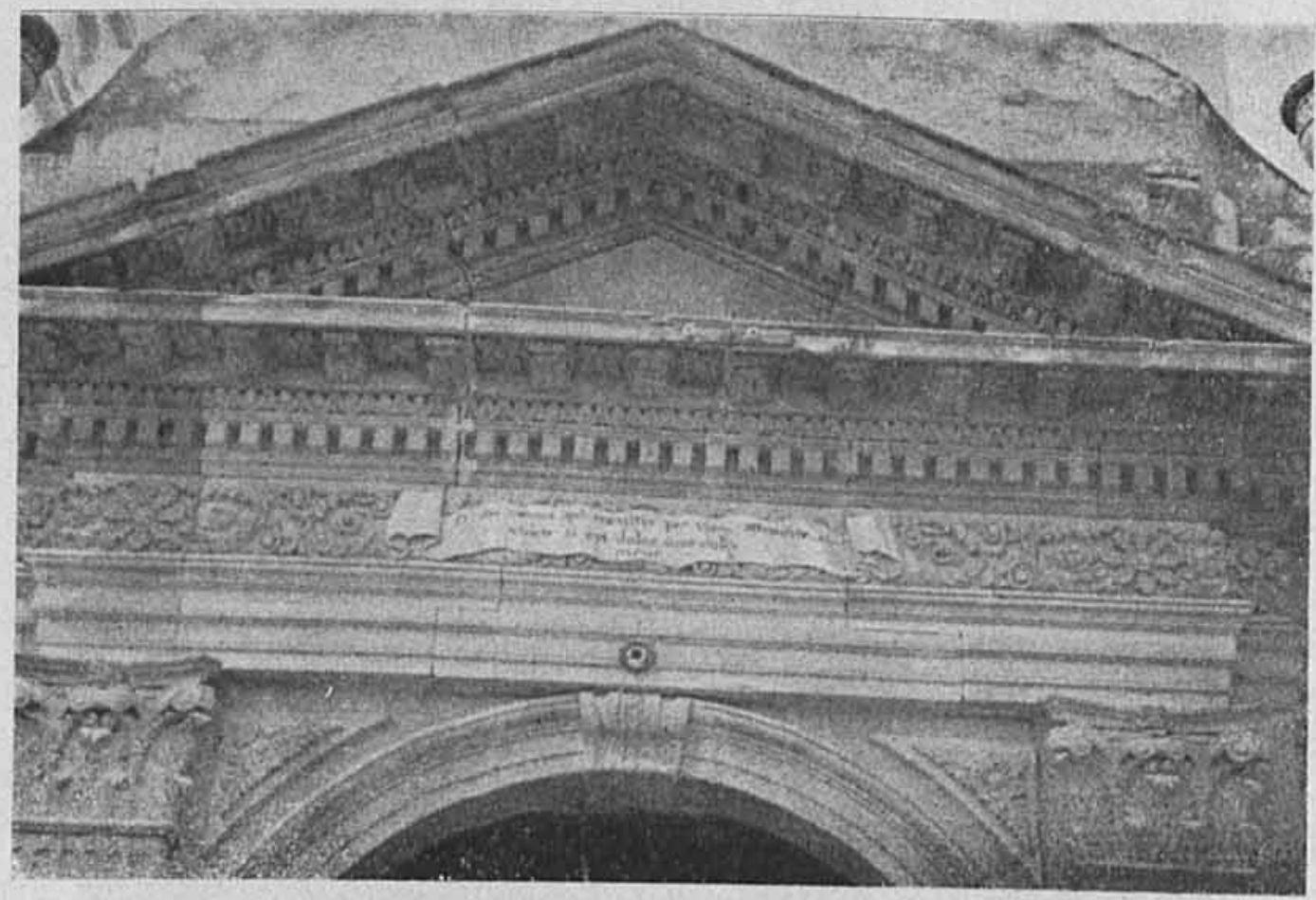

2. Cornisa y frontón de la fachada.

(Foto R. Flores Guerrero.) 
DOI: http://dx.doi.org/10.22201/iie.18703062e.1951.19.519

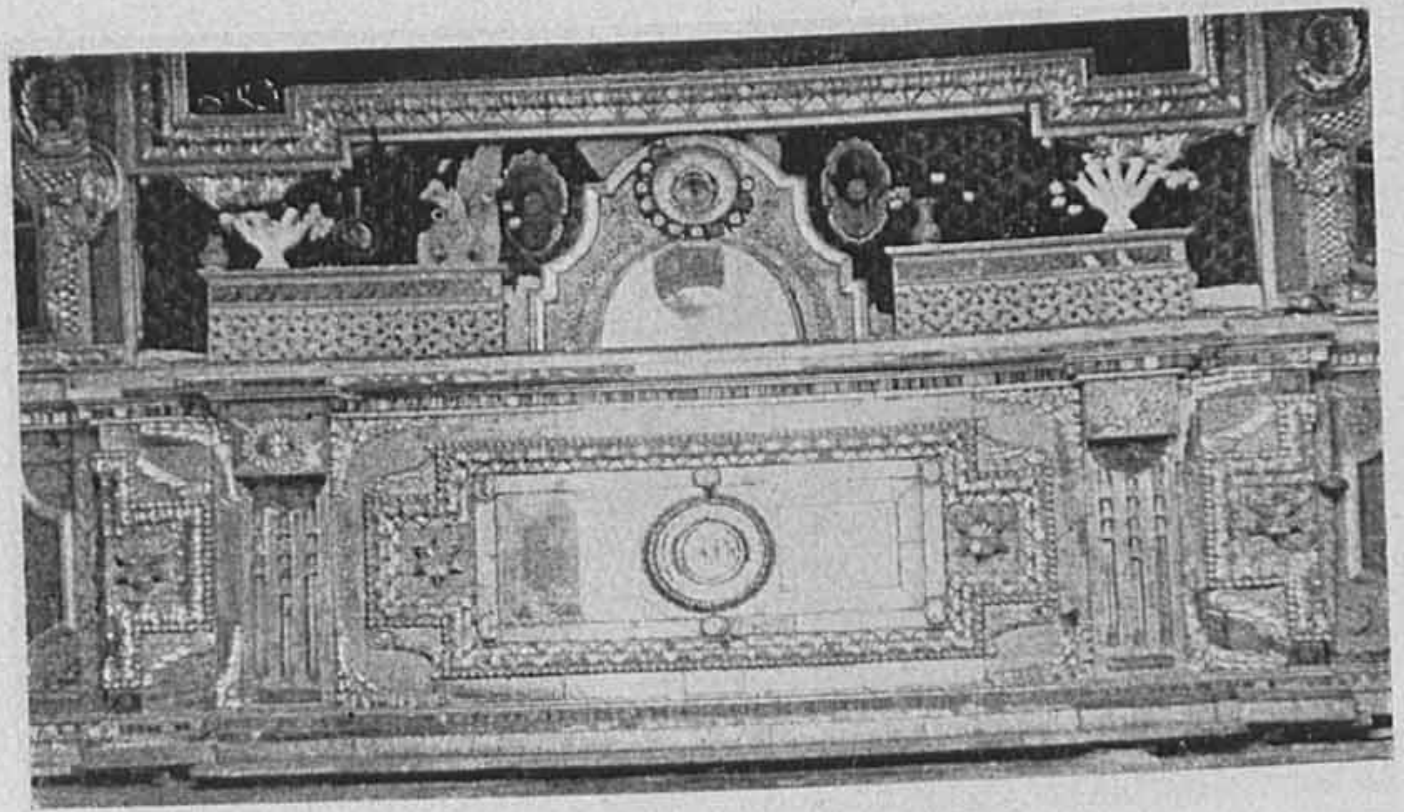

3. Mesa del altar de la capilla.

(Foto R. Flores Guerrero.) 
DOI: http://dx.doi.org/10.22201/iie.18703062e.1951.19.519

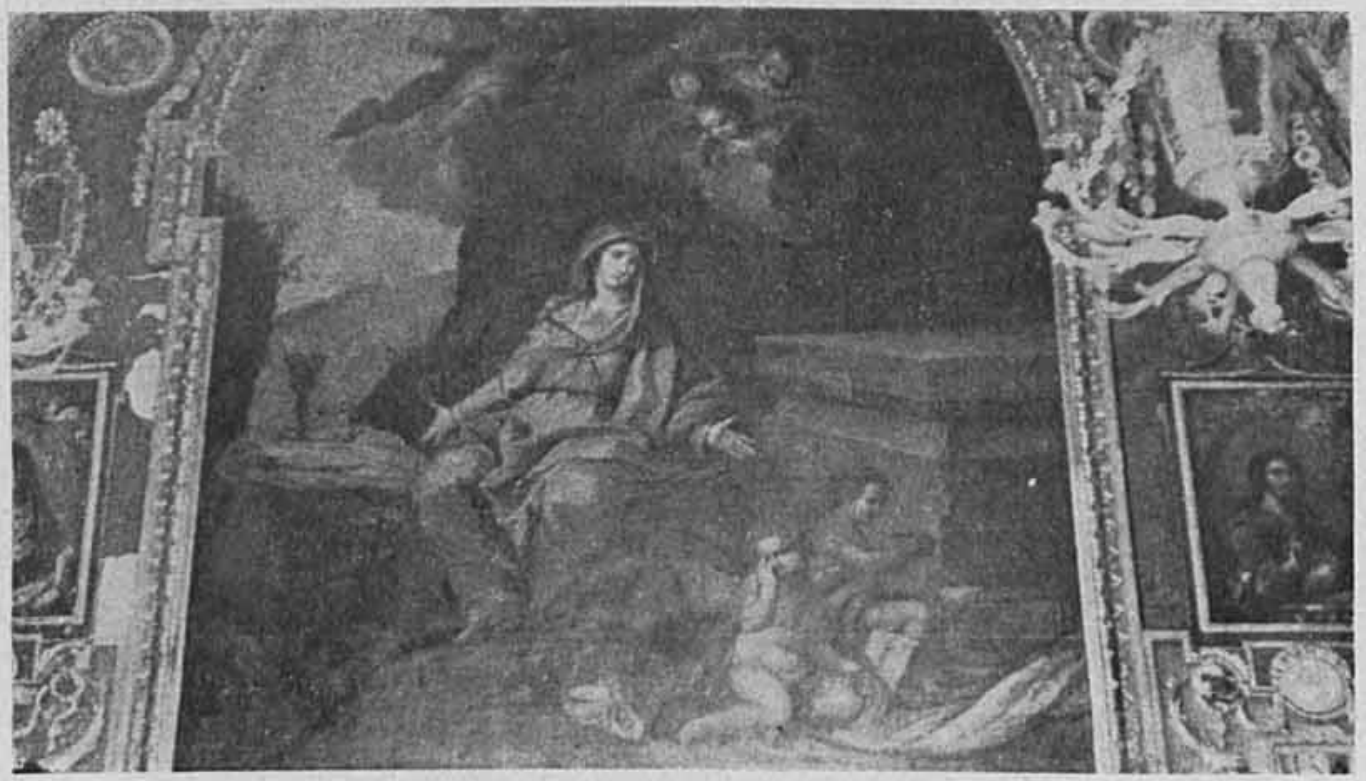

4. Pintura de la Virgen de los Dolores en el altar.

(Foto R. Flores Guerrero.) 
DOI: http://dx.doi.org/10.22201/iie.18703062e.1951.19.519

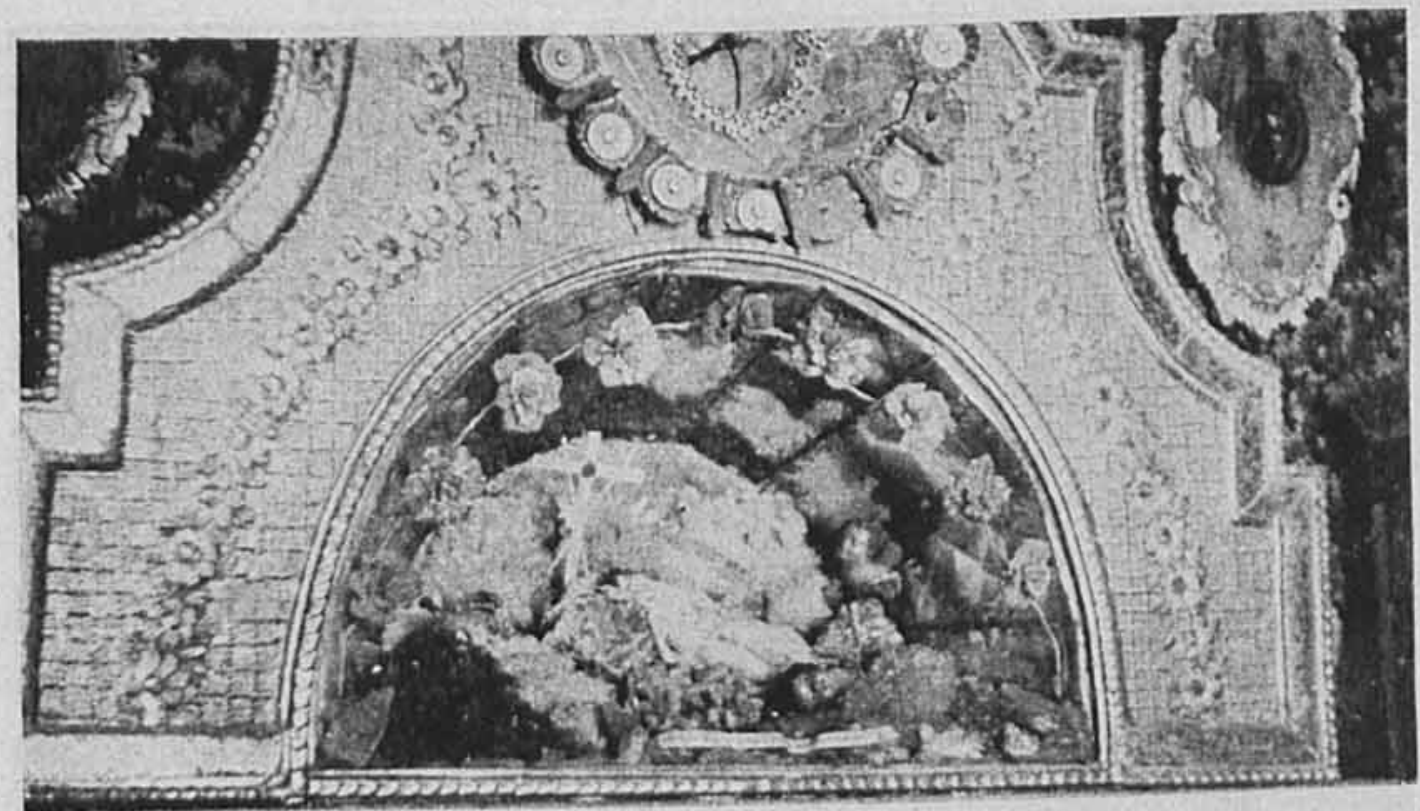

5. Nicho con el Niño Dios de alabastro.

(Foto R. Flores Guerrero.) 
DOI: http://dx.doi.org/10.22201/iie.18703062e.1951.19.519

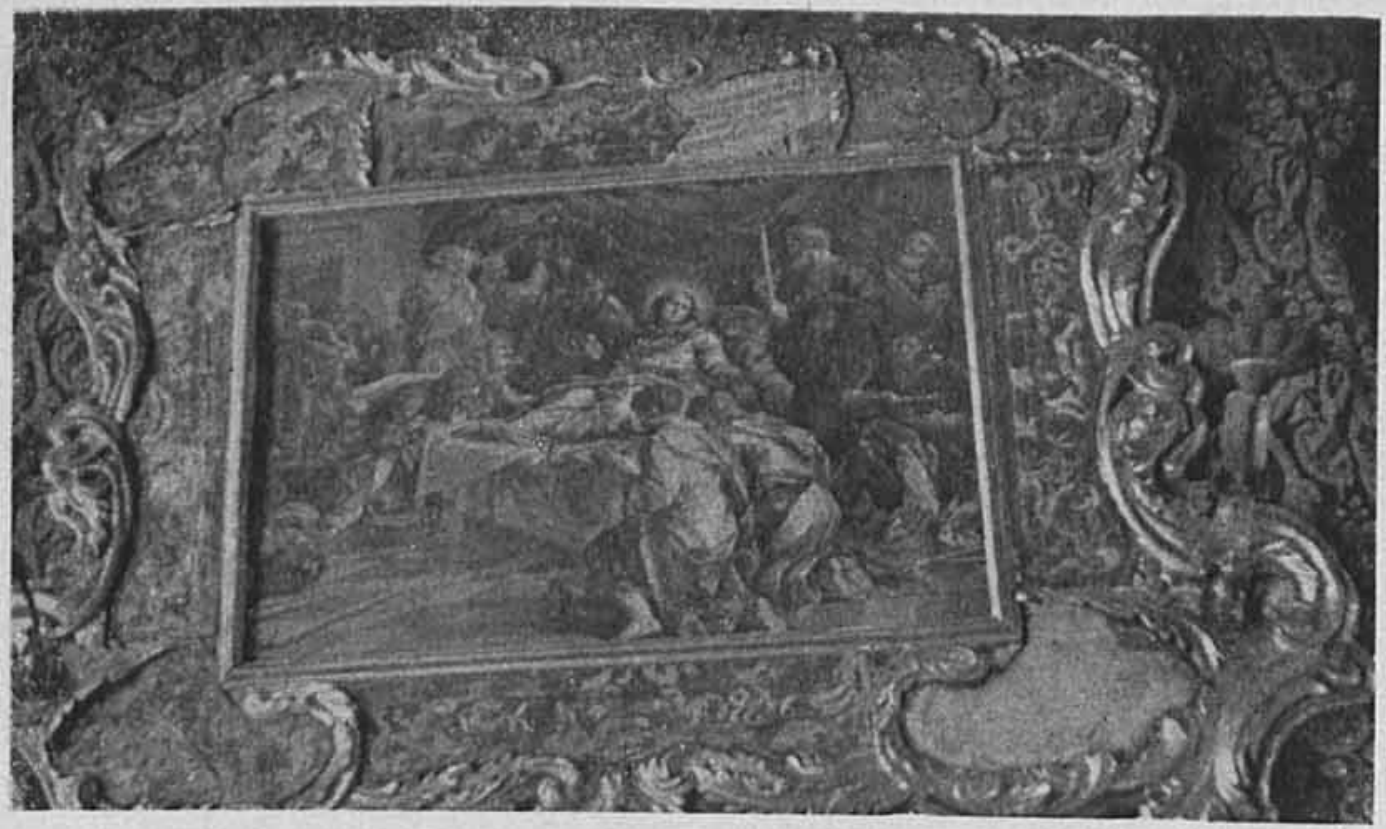

6. Grabado italiano del siglo xvmr.

(Foto R, Flores Guerrero.) 
DOI: http://dx.doi.org/10.22201/iie.18703062e.1951.19.519

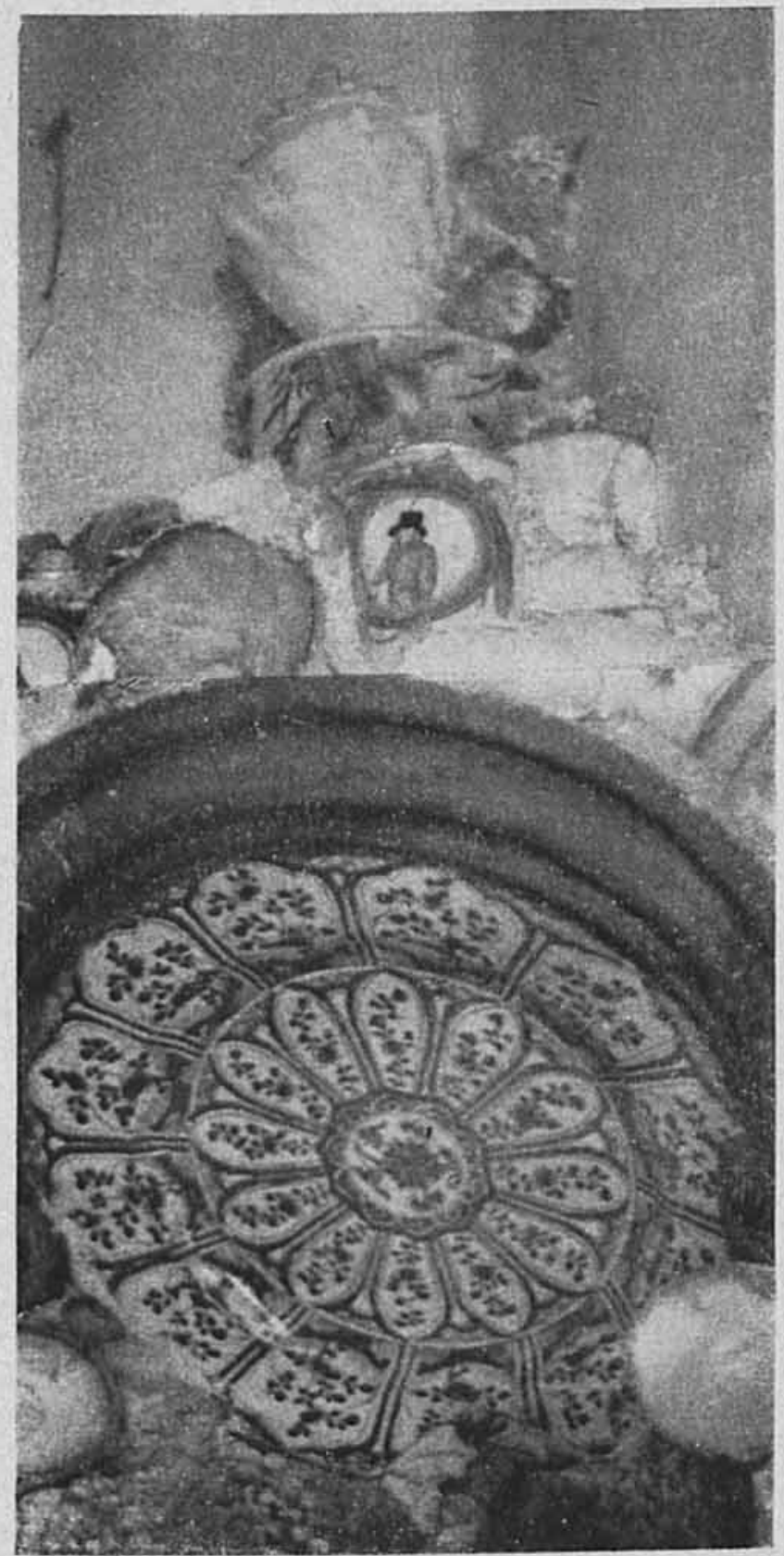

7. Lavabo de la sacristia. (Parte Superior.) (Foto R. Flores Guerrero.) 